gastric region. Jolly and Georget also use this term, and note its frequency in women during the reproductive period of life, or whenever the system is strongly reacted on by the reproductive apparatus. Lonyer Villermay gives cases in which hysteria is accompanied by attacks of intense epigastric pain, exhaustion, syncope, or suffocation. Dr. Addison has not exaggerated the frequency of cardialgia in those suffering from uterine affections; and Hufeland and Chambon state that, at the change of life, women are subject to suffocation and epigastric spasms. Dusourd, remarking on the same phenomena, correctly says, " they simulate asthma," and adds, that, "the affections and sensations at the pit of the stomach at the change of life baffle description."

A valuable contribution to neural pathology has recently been made by Dr. Shearman, who has evidently been forcibly struck by cases similar to the preceding. Bearing in mind the fact, already well established by Romberg, that neuralgia of the vagus nerve is indicated by patients becoming ravenous, who could previously take only the smallest quantity of food; and coupling this with Bernard's discovery, that irritation of the origin of the vagus caused sugar to form in the liver, which was removed by the kidneys, and appeared in the urine, Dr. Shearman "concluded that the disease was one of the vagus nerve in some parts of its tract, either centric, peripheral, or intermediate; of irritation in its early stages, and of palsy succeeding to that irritation." He designated it sinking dyspepsia, and treated it as he would the neurosis of any other centripetal nerve. If I be not deceived, Dr. Shearman has exaggerated the frequency of neurosis of the vagus, describing as such those cardidlgic affections which are more or less complicated by reflex neuralgia of the vagus nerve. The vagus is a bridge by which the central portions of the two nervous symptoms are placed in communication. Uniting both nervous systems it resembles both, but principally the sympathetic, by its organization and the modes of its distribution. It is not a well isolated nerve, for it often anastomoses with the sympathetic, and helps to form the cœliac ganglion, by nerves which are both numerous and voluminous. Thus anatomically united, I believe the affections of the vagus and the epigastric ganglia generally coincide.

Such is the language of previous authors and the views of fellow-practitioners with regard to the disease under consideration; I shall, in a concluding paper, brietly deseribe the neuralgia of the central ganglia and plexus, using the old term, cardialgia, because it is generally understood to mean epigastric pain with sensations of debility.

(To be concluded.)

ON THE

\section{TREATMENT OF CARBUNCLES AND BOILS.}

\section{By JOHN HIGGINBOTTOM, Esq., F.R.S., F.R.C.S.}

DURING the first twenty years of my practice, I pursued the following mode of treatment of carbuncles:-First making a free incision through the whole substance of the carbuncle, I afterwards applied a common poultice for a few days, until the surrounding inflammation had subsided, and then daily applied the resin ointment. I paid particular attention to the digestive organs, prescribing ipecacuanha emetics, aperients, simple diet, and pure air.

During the next twenty years, I pursued the same practice, with the addition of the application of the nitrate of silver, or lint imbued with it and dried, over the surface of the ulcer and surrounding inflamed skin, instead of the resin ointment, and then a poultice.

During the last six months, I have been greatly interested in the effect of the treatment proposed by the late Dr. Physick, of Philadelphia, by the hydrate of potash, substituted for the knife, a practice which prevents all loss of blood, an object of great importance when the carbuncle is very large, and the patient old and weakly. This method of treatment would have been very desirable in the case of a large carbuncle, of no less than seven inches in diameter, which I had occasion to treat many years ago. The patient was a publican, of great obesity, and of a pale, unhealthy aspect, and could ill bear the loss of blood, and the case had been greatly neglected.

My object in this paper is to detail the result I have obtained by combining the plan recommended by Dr. Physick with that by the nitrate of silver.

An old man of eighty-four years of age had a large carbuncle, situated on the outer side of the left thigh; it was proceeding very rapidly, and was attended with much pain and surrounding inflammation. I first applied the nitrate of silver as in external inflammation, on and beyond the whole hardened and inflamed surface, round the carbuncle; and then the hydrate of potash freely on the sieve-like surface of the carbuncle, and over it a piece of lint; and lastly, over all, a common poultice, which should be renewed every eight hours. I prescribed a gentle aperient, and directed a plain, simple diet. The progress of the carbuncle was immediately arrested, and the inflammation and hardness had disappeared on the fourth day, the period the nitrate of silver also loses its effects on the skin. The slough separated in about a week, and the ulcer healed in about five weeks.

The effect of the hydrate of potash in destroying the substance. of the carbuncle is admirable.

I may add, in conclusion, $I$ have often used the hydrate of potash in diseased growths with great advantage, and, with common care in the application, it does not injure the surrounding skin ; indeed, I have remarked the complete destruction of the diseased growth, leaving the surrounding skin in a healthy state.

The difference of the effects of the nitrate of silver and of the hydrate of potash is very manifest in the case of carbuncle, the former being a preservative, the latter a destructive, agent. This distinction is all-important.

In the incipient state of both boils and carbuncles, before the skin is broken, the application of the nitrate of silver, applied as in external inflammation, will often arrest their progress.

During long experience, I have never prescribed alcoloolic stimulants, and I have not seen a fatal case of carbuncle. I have found it much better and safer to pursue the plan of inducing a healthy state of the digestive organs. Where a tonic is required, quinine, with compound infusion of orange-peel and dilute sulphuric acid, is the best.

In a paper by Benjamin Travers, jun., Esq., published in January last, "On the Treatment of Boils and Carbuncles by the Hydrate of Potash," he concludes by saying, "I find from the report which I lately read in a newspaper, that in 1854 there occurred ninety deaths from carbuncle in the metropolis alone."

Nottingham, November, 1856.

\section{THE "READY METHOD" IN ASPHYXIA.} SUCCESSFUL RECOVERY AFTER ORDINARY MEANS, TRTED FOR AN HOUR, HAD FAILED.

By A. LEGAT, M.D., South Shields.

Havirg had occasion to visit a lady, three or four miles distant, on the 3rd instant, as I drove to the door I was requested to go immediately to the coach-house to see "an extreme case." On entering the harness-room, I saw stretched on his back before a warm fire, partially enveloped in blankets, a muscularlooking young man, surrounded by four or five others, one of whom was supporting his head. The lips and face were blue, the surface quite cold, and the body so rigid that the right hand, which rested over the pubis, and the left arm, bent at right angles over the chest, could not without difficulty be changed from their position. There was no pulse, and no respiration conld be detected. A slight quivering was ohserved throughout the body for an instant, and in this movement seemed the only hope that life might be restored. Exactly an hour had elapsed since he was taken out of the sea, and at that time he spoke a few words. Blankets were taken down to the beach. He was well rubbed. An attempt was made to administer brandy, which it would appear he could not swallow, and he was then carried about four hundred yards to the room where I found him. He had been lying here about half an hour, during which time lee had not spoken, and for the last ten minutes of it he had been in the condition above described. Those around him told me "they feared it was too late to be of use to him." I felt there was no time to be lost. The window of the room was ordered to be thrown open, and placing my watch on the floor before me, for the purpose of correct observation, I knelt down, and with my right hand on his left shoulder, and my left on the side of his chest, commenced the movements desi ribed by Dr. Marshall Hall. He was rolled gently over on his face, (the mouth and nostrils being carefully 